\title{
The Role of Public Health Within the United Nations Post-2015 Framework for Disaster Risk Reduction
}

\author{
Virginia Murray • Amina Aitsi-Selmi • \\ Kevin Blanchard
}

Published online: 13 February 2015

(c) The Author(s) 2015. This article is published with open access at Springerlink.com

\begin{abstract}
This article explores the role of public health systems before, during, and after disasters, particularly within the scope of the United Nations Post-2015 Framework for Disaster Risk Reduction. It also examines the role of scientific and technological developments in assisting with improving the resilience of public health professionals and the communities they work in. In addition, it explores how the wide-ranging activities in public health have already contributed to the improved management of disasters and a decrease in associated risks. The article identifies areas of synergy in five key areas of recent policy and practice in public health (the health systems approach, risk assessments, the WHO/UNISDR/HPA Disaster Risk Management fact sheets, chronic disease and disasters, and mental health impacts following disasters) and makes suggestions based on lessons identified from the previous (2005) global disaster risk reduction framework. In particular, we advocate the use of scientific evidence that addresses health and disaster risk simultaneously to increase the effectiveness of policy and practice in disaster risk reduction, health, and public health.
\end{abstract}

Keywords Disaster risk reduction - Health systems · Post-2015 framework · Public health · Risk assessments

\section{Introduction}

The year 2015 will be marked by three landmark United Nations (UN) agreements: the Post-2015 Framework for Disaster Risk Reduction (that will cover the next 10-20 years and is scheduled for March 2015) (UN 2013); the Sustainable Development Goals (September 2015) (UN 2014a); and the climate change agreements through the United Nations Framework Convention on Climate Change (UNFCCC) (December 2015). There are ongoing efforts to create convergence between these three global policy frameworks and health represents a cross-cutting theme. Better population health and well-being is an integral aim of public health and an important outcome for the post-2015 UN agenda in its own right. But it is also a potential point of convergence of the three separate post-2015 agreements.

To achieve the best overall outcomes, an understanding of how population and public health are included and can be further strengthened as a theme in these global agreements is imperative, and opportunities exist for public health professionals to participate and contribute. This article addresses the role of public health in disaster risk reduction (DRR) and identifies how the public health theme has been articulated in the development of the Post-2015 Framework for Disaster Risk Reduction, and how the post-2015 agenda can be strengthened by building on synergies between DRR and public health. The article also highlights the wider role of science-a strong tradition in public health-and where DRR can build on good practice in public health.

\section{What is Public Health?}

The World Health Organization (WHO) defines public health as "all organized measures (whether public or 
private) to prevent disease, promote health, and prolong life among the population as a whole" (WHO n.d.). Public health focuses on activities that provide conditions in which people can be healthy and on entire populations, not individual patients. Public health is increasingly concerned with the total health system and not only the eradication of a particular disease. All three public health functions are of importance for disaster risk reduction (DRR), and these are summarized as (WHO n.d.):

- The assessment and monitoring of the health of communities and populations at risk, to identify health problems and priorities

- The formulation of public policies designed to solve identified local and national health problems and priorities

- To assure that all populations have access to appropriate and cost-effective care, including health promotion and disease prevention services.

Conversely, the continued delivery of these public health functions relies on adequately addressing disaster risk from prevention to response. The term "global public health" recognizes that, as a result of globalization, forces that affect public health can and do come from outside state boundaries and that responding to public health issues now requires attention to cross-border health risks which can include (but are not limited to) environmental change, infectious diseases, and interdependence in terms of communications and trade, which can be severely disrupted during disasters and affect the livelihood and well-being of local communities.

The breadth of public health activities is illustrated by notable public health campaigns that link to DRR and these include immunization campaigns for infectious disease outbreaks. Areas of policy and practice where public health expertise has contributed or will be able to contribute to reducing disaster risk and its impacts as well as improving its management include:

- The health systems approach;

- Risk assessments;

- WHO/UNISDR/HPA disaster risk management fact sheets;

- Chronic disease and disasters;

- Mental health impacts following disasters.

\section{The New (Post-2015) Framework for Disaster Risk Reduction and its Relationship to Public Health}

Disasters affect human lives around the world by causing injury and long-term impacts as well as destroying lives and livelihoods. A reported 1.7 million people were killed in disasters between 2000 and 2012, and an estimated USD 1.7 trillion of damage were sustained (UNISDR 2013).

In 2005, the 2nd World Conference on Disaster Reduction in Kobe, Japan, adopted the Hyogo Framework for Action 2005-2015: Building the Resilience of Nations and Communities to Disasters (HFA). The Hyogo Framework for Action (HFA) was unique in that it was the first plan to coordinate information, research, and best-practice in order to reduce the losses associated with disasters. This coordination involved multiple actors including governments, international agencies, disaster experts, and many others (UNISDR 2007). However, the absence of health/public health as an explicit component is considered to have diminished the overall conceptual framework for action.

What does disaster risk reduction (DRR) mean to public health professionals? Disaster Risk Reduction activities are broad and aim to reduce the impacts from disasters with respect to loss of life, injury, and other health impacts as well as on the wider socioeconomic determinants that affect population health including property damage, loss of livelihoods and services, social and economic disruption, and environmental damage. The use of scientific evidence to inform policy priorities and formulate effective initiatives and interventions is crucial to DRR, as it has been to public health in reducing the global burden of infectious diseases, including HIV, as well as improving maternal and child mortality globally (CDC 2011). To build knowledge that can be useful and usable in the broad and complex landscape that links environmental and societal impacts to population health, "science" should be considered in its widest sense to include the natural, environmental, social, economic, population health, and engineering sciences, and scientific capacities should be interpreted broadly to include all relevant resources and skills of a scientific and technical nature that can reduce the impact of disaster hazards (Basher 2013).

Science can play an essential role in DRR efforts to minimize harmful public health (and other) impacts, by helping to inform policies and practices; uncovering new ways to prevent, prepare for, and respond to disasters; and determining which technologies are most effective in reducing disaster risk. As a result of ongoing research and science-translation into usable knowledge for policymakers, science and technology are already helping to save lives and protect livelihoods through programs to prevent infectious disease outbreaks with vaccinations, forecasting floods, detecting tsunamis, and effectively communicating disaster risk to enhance community resilience.

The importance and necessity of this effort was further underscored by the fact that the conclusion of the United Nations International Strategy for Disaster Reduction (UNISDR) Scientific and Technical Committee report Using Science for Disaster Risk Reduction included a di- 
rect call for a greater use of science in DRR, and during the closing comments of the May 2013 Global Platform recommendations were made to include science more regularly because it is not used enough to help reduce disaster risks (Southgate et al. 2013).

Taking the principles of an enhanced scientific function in DRR to regional platforms on disaster risk reduction between May and July 2014 - to Africa (UN 2014b; UNISDR 2014a), the Americas (UN 2014c; UNISDR 2014b), the Pacific (UN 2014d) and Asia (UN 2014e; UNISDR 2014c), and the European Ministerial Meeting (UN 2014f) - revealed much support for the approach and indicated that the policy community is receptive to an enhanced role of science in DRR. Health issues were a strong focal point of discussion based on the evidence of significant health impacts of disasters. Important areas of synergy and potential for strengthening collaboration between DRR and the health sector were articulated at these meetings:

- The Africa Regional Platform in May 2014 stated that "Health is an imperative for disaster risk reduction and community resilience. Health status and targets should be among indicators for monitoring and reporting on disaster risk reduction achievements." (UN 2014b)

- The Americas Regional Platform in May 2014 addressed health as a sector in particular (UN 2014c):

- Note that $89 \%$ of the countries in the Americas are implementing national initiatives on safe hospitals and improving the resilience of new and existing health care services in order to ensure continuity of operations in the event of a disaster.

- Affirm that protecting essential services, particularly schools and hospitals, is a social priority, a collective and political responsibility and is crucial for achieving resilient communities.

- Establish the development and implementation of safe school and hospital policies and programs as a priority for action at the local, national and regional levels in order to protect and guarantee access to education and health services before, during and after disaster situations, as a contribution towards the achievement of the millennium development goals.

During the discussions at the Regional Platforms, the World Health Organization (WHO) worked in partnership with many representative organizations ${ }^{1}$ that have been

${ }^{1}$ List of agencies contributing to Health and Disaster Risk.

- The WHO commitment to DRR is prescribed by the World Health Assembly (WHA) and Regional Committee Resolutions and in the Emergency Risk and Crisis Management and other program areas of WHO's Medium-Term Strategic Plan (MTSP) for 2014-2019.

- International Federation of Red Cross and Red Crescent, International Rescue Committee, Save the Children, UNISDR, instrumental in promoting their recommendations for the active consideration of health in DRR (UN 2014g). This has been a valuable part of the UN landmark agreements and has helped to clarify the role of health, both as an outcome and as a sector.

It was recommended, for example, that the 2005 International Health Regulations (IHR) (WHO 2005b) should be linked to the next framework on DRR to provide an international mechanism for the early detection and assessment of, and rapid response to public health emergencies with the potential for international spread. The IHR provide a legal mandate for countries to comply with capacities for the management of events which may constitute a public health emergency of international concern. In the January 2015 negotiations, the IHR were provisionally agreed for inclusion in the Post-2015 Framework for Disaster Risk Reduction. The intention is also to enhance the resilience of national health systems, including the integration of DRR into health care planning and capacity building, especially at local levels. Examples of how this might be achieved include developing the capacity of health workers in understanding disaster risk; applying and implementing disaster risk reduction approaches into health work; and supporting and training community health groups in disaster risk reduction approaches in collaboration with other sectors.

The proposed requirements to enhance recovery schemes to provide psychosocial support and mental health services for all people in need are also included in the current draft of the post- 2015 agreement. The necessity to recognize people with chronic disease because their particular needs can be life threatening without medication should be included in the design of policy and plans to manage their risks before, during, and after disasters, including access to life-saving services.

Despite the considerable work already undertaken, more can be done, and UNISDR has called for coherence and mutual reinforcement of the UN landmark agreements, between the Post-2015 Framework for Disaster Risk Reduction, Sustainable Development Goals, and the Conference of Parties to the UNFCCC in April 2014 (UNISDR 2014d). This was addressed in part at Prepcom 1 in July

Footnote 1 continued

UNICEF, WHO, WMO, academic institutions and other partners collaborate on various programs in support of Ministries of Health, and other national community actors for disaster risk management (DRM). Many partners contribute to the WHO/ UNISDR thematic platform for Emergency and Disaster Risk Management-Health (EDRM-H) and the Global Health Cluster for humanitarian response.

- The Towards a Safer World Initiative convenes a broad range of multisectoral, multiregional stakeholders with the goal of more effective whole-of-society preparedness to lower the economic, social, and humanitarian impacts of pandemics and comparable high-impact risks. 
2014, at Prepcom 2 in November 2014, and at the negotiations in January 2015. The negotiations on the Post-2015 Framework for Disaster Risk Reduction are likely to continue up to the Third World Conference on Disaster Risk Reduction in Sendai, Japan, in March 2015.

\section{Learning from Public Health: Enhancing the Role of Science to Deliver Effective Disaster Risk Reduction Policy and Practice}

Science clearly underpins much of health and public health practice and the evidence-based medicine and policy movements have grown over the last two decades in many parts of the world (Young et al. 2002; Greenhalgh 2014). Despite persistent challenges, this has led to improved outcomes for people over time by implementing more consistent, safe, and effective policies and practices that affect individual and population health. The application of evidence-based medicine that is closely linked to public health practice achievements includes the establishment of the Cochrane Collaboration to collate and summarize evidence from clinical trials (The Cochrane Collaboration 2014); setting up the National Institute of Health and Care Excellence to assess the cost-effectiveness of interventions (NICE 2014); setting methodological and publication standards for primary and secondary research; building national and international infrastructures for developing and updating clinical practice guidelines; developing resources and courses for teaching critical appraisal; and building the knowledge base for implementation and knowledge translation (World Health Assembly 2011). A similar movement has been evolving in DRR as well, including a growing role for a number of scientific approaches such as climate forecasting and sophisticated earth observation tools, collating information in centralized locations for policy-makers and researchers - such as PreventionWeb (2014), Global Facility for Disaster Reduction and Recovery (2014), Global Earthquake Model (2014), and Evidence Aid (2014) — but also at a social science level including UNISDR Science and Technology Group case studies examining better understanding of communication patterns and crowd behaviors during disasters (Drury et al. 2014).

In seeking to support this trend to use science to protect and empower people, the UNISDR Scientific and Technical Advisory Group (UNISDR STAG) in collaboration with the Major Group on Science and Technology (UN 2014h) has made a voluntary commitment for an international partnership to mobilize science for action on DRR and resilience building. It brings together these groups' commitment to work together to ensure science, engineering and technology, as well as health science, are embedded into disaster risk.
Scientific data, information, and tangible application of technology are critical to underpinning well-informed policies and decisions across the public, private, and voluntary sectors. Much scientific evidence exists, but better links to policy- and decision-making processes are needed to continuously enhance our ability to forecast, reduce, and respond to disaster risks and build resilience. Science and technical communities wish to strengthen the dialogue and collaboration with policy-makers and DRR practitioners at local, national, regional, and global levels to not only identify needs and knowledge gaps but also work to codesign, co-produce, and co-deliver new usable knowledge, make scientific findings more readily available/accessible, and, in particular, deliver outputs in six areas of activity (see Sect. 6).

\section{Examples of Areas of Synergy Between Public Health and Disaster Risk Reduction}

In this section, five key synergy areas of public health science and DRR are addressed in the value of the health systems approach; risk assessment use; multi-stakeholder (WHO/UNISDR/HPA) disaster risk management fact sheets; vaccination and control of infectious diseases; the vulnerability following disasters of those with chronic diseases; and the mental health impacts of disasters.

\subsection{The Value of the Health Systems Approach}

Health systems can be defined as the structured and interrelated work of all agencies contributing to health within a country and includes efforts to influence determinants of health as well as more direct health improving activities (WHO 2007). The WHO describes six building blocks or "levers" that are related in a dynamic interdependent manner: (1) Service delivery; (2) Health workers; (3) Health information; (4) Medical products, technology, and vaccines; (5) Health finance; and (6) Governance and leadership.

Disaster management is a global issue and countries are being encouraged to improve their disaster preparedness, along with a growing international commitment to strengthen health systems. The World Health Organization's 64th World Health Assembly in May 2011 adopted a resolution on strengthening national health emergency and disaster management capacities and resilience of health systems (World Health Assembly 2011). Lessons identified from disasters have not been effectively collated and essential experience is considered to have been forgotten. Bayntun (2012) emphasized that a holistic health system approach to disaster management has not been established in practice or evaluated in the core literature. Analysis of 
the disaster management literature identified how a strengthened health system can promote resilience and an efficient recovery in the face of disasters (Bayntun et al. 2012).

The WHO Regional Office for Europe has adopted health system strengthening as an approach to support emergency preparedness and enhancement of crisis management capacities of member states and this approach supports and complements the organization's toolkit (WHO Europe 2012a; WHO Europe 2012b). In response to international requests, this practical, action-oriented toolkit was developed and refined (during the course of pilot assessments carried out between 2007 and 2010) in a series of expert consultations. Countries can use the WHO toolkit and its specific guidance on writing assessment reports to assess their disaster management capacities and identify priorities for strengthening their health systems.

A report using the WHO toolkit to evaluate England's health system arrangements to deal with crises, risk prevention, and mitigation initiatives was submitted in January 2012 by the Health Protection Agency (now known as Public Health England) to WHO Regional Office for Europe and the UK Department of Health. The findings concluded that the National Health Service (NHS) in England is largely integrated in regard to disaster management and identified that the structured response system which involves multisectoral collaboration and coordination is beneficial (WHO Europe 2011).

Power outages are an example of a health systems specific issue. Extreme events (flooding, strong winds and so on) threaten critical infrastructure including power supplies. Electricity was recognized by the UK Department of Health as the "most vital of all infrastructure services" because "without it most other services will not function" (UK Department of Health 2007). Many interlinked systems in the modern world depend on a reliable power supply to function effectively, and the health sector is no exception. But the impact of power outages on health is poorly understood. Klinger et al. (2014) found that power outages impact health at many levels within diverse settings, including the difficulties of accessing health care, maintaining frontline services, and addressing the challenges of community health care such as the provision of electrically generated home oxygen supplies. A survey conducted in Japan, for example, found that $65 \%$ of disaster base hospitals (that is, hospitals responsible for supporting other hospitals during a disaster) considered electricity to be the most vital lifeline for the functioning of their hospitals; $60 \%$ of these hospitals indicated that key services such as emergency surgery and dialysis would have to be stopped if generator power was unavailable. Key equipment related to services such as laboratories, imaging, and sterilization would also stop if generators failed
(Klinger Klinger et al. 2014). Most hospitals have generator backup for only eight hours. During longer-term power outages hospitals can be faced with limited fuel and difficulties in sourcing fuel for generators. This is a particular issue if transportation and communication services are disrupted as well. The survey also found that the current evidence and knowledge base is poor (Klinger Klinger et al. 2014).

With scientific consensus predicting an increase in the frequency and magnitude of extreme events due to climate change, the gaps in knowledge need to be addressed in order to mitigate impacts of disasters in global health systems.

\subsection{Risk Assessments}

In the Intergovernmental Panel on Climate Change (IPCC) Special Report on Managing the Risks of Extreme Events and Disasters to Advance Climate Change Adaptation, the balance between reducing risk and other disaster risk management strategies is influenced by a range of factors, including the financial and technical capacities of stakeholders, the robustness of the risk assessment information, and cultural elements involving risk tolerance (IPCC 2012). Therefore risk assessment is a key tool, particularly to inform public health risks.

Recognizing that most countries continue to have difficulties integrating risk reduction into public investment planning, urban development, spatial planning and management, and social protection, the European Commission (EC) has promoted the use of risk assessment and analysis. An EC report stated that data derived from past losses are useful for the implementation of disaster risk reduction strategies in Europe (from local to national scales) and to help understand wider disaster loss trends at the global level (De Groeve et al. 2013). The report emphasized that risk modelling is a valuable tool for improving risk assessment and forecast methods, but loss datasets are needed for calibrating and validating model results, in particular to infer vulnerabilities.

By building on the available national risk assessments, the EC has prepared the first cross-sectoral overview of risks in the EU, taking into account (where possible and relevant) the future impact of climate change and the need for climate adaptation. Following a consistent approach, multi-hazard national risk assessments are to be produced by Member States by the end of 2015 and followed up by an assessment of national risk management capabilities and improved risk management planning (European Commission 2014a). The EC reported that of the 32 countries participating in the Mechanism for Civil Protection, 18 contributed to the review through their national risk assessments (NRAs) (European Commission 2014b). Of 
these, nine Member States provided information on their national assessment criteria and scenario-building. The EC concluded that more systematic and complete information on the assessment criteria and on the risk scenarios assessed may help the Commission carry out an informed and coherent analysis of risks addressed in NRAs (European Commission 2014b).

The UK's National Risk Register of Civil Emergencies aims to understand disaster risks and determine their relative significance in terms of potential impact, and provides the starting point for emergency planning. Key to ensuring useful planning information is the understanding that it is not the risks themselves that people have to deal with when things go wrong, but their consequences. In an increasingly complex and interdependent society, emergencies can have increasingly multifaceted and wide ranging effects. The Register identifies both direct and indirect consequences, many of which are common to several risks, and provides information on how to prepare for them. The UK National Risk Register of Civil Emergencies has been published since 2008. In the July 2013 edition the Register provides an updated government assessment of the likelihood and potential impact of a range of different civil emergency risks (including naturally and accidentally occurring hazards and malicious threats) that may directly affect the UK over the next five years. The Register also provides information on how the UK government and local responders such as emergency services need to prepare for these emergencies (UK Government Cabinet Office 2013). For the public health community in the UK, pandemic influenza remains the most significant civil emergency risk.

An additional area of policy and research importance in DRR, including risk assessment, is the role of inclusion and combating inequality, specifically how to ensure that vulnerable groups are given full consideration as risk is unevenly distributed. This converges with a growing interest in the global public health sector into the inequalities in the distribution of health and disease and the role of socioeconomic factors and other dimensions of inequality including age, disability, and gender through the societal factors that affect health (WHO 2008). For example, disasters can have systematically unequal impacts by gender before, during, and after a disaster event. The role of gender in a particular society often means separate or varying levels of access to health care services, social support systems, and in some cases, access to aid relief (WHO 2002). The gender mix of the affected community can also impact the types of services those working within the health system will be required to provide. In poorer countries, for example, pre- and post-natal care can be challenging even without the added strains of a disaster. Lack of basic facilities that may have been destroyed or damaged make the delivery of a child under these circumstances even more precarious and put mothers and children at high risk (Nour 2011). The WHO has developed several documents relating to the role of gender in the aftermath of disasters (WHO 2005a) and highlighted that recognition of the potential gendered issues that may be encountered during disasters will assist with the swift and effective implementation of health services in response and recovery (WHO 2005c).

\subsection{WHO/UNISDR/HPA Disaster Risk Management Fact Sheets}

Because disasters and other emergencies often result in significant impacts on people's health, WHO/UNISDR and the Health Protection Agency (HPA)-Public Health England (PHE) since 2013-developed a series of Disaster Risk Management for Health Fact Sheets (WHO et al. 2012).

Every new threat reveals the challenges for managing health risks and the effects of emergencies and disasters. Deaths, injuries, diseases, disabilities, psychosocial problems, and other health impacts can be avoided or reduced by disaster risk management measures involving the health and other sectors. These advocacy materials of the Disaster Risk Management for Health Fact Sheets were written as an introduction for health workers engaged in disaster risk management and for multisectoral partners to consider how to integrate health into their disaster risk management strategies. An overview places disaster risk management in the context of multisectoral action and focuses on the generic elements of disaster risk management, including potential hazards, vulnerabilities of a population, and capacities across the health system. Each fact sheet identifies key points for consideration within a number of essential health domains. Because all health domains are interlinked each fact sheet should be considered as part of the entire set and in conjunction with the overview and a summary of definitions in the natural hazards fact sheet.

Within a short, easy to read document (two sides of a single page) the fact sheets address the key points including why the hazard is important, the health risks, and the risk management considerations, and provide key references and suggested further reading. The fact sheets address the following topics: chemical safety; child health; climate risk management; communicable diseases; mass casualty management; mass fatalities/dead bodies; mass gatherings; mental health; non-communicable disease; nutrition; people with disabilities and older people; radiation emergencies; safe hospitals prepared for emergencies and disasters; sexual and reproductive health; and water, sanitation, and health. For the public health community these fact sheets have provided useful teaching resources. 


\subsection{Chronic Disease and Disasters}

People with life threatening and chronic diseases, due to their particular needs, must be included in the design of policies and plans to manage their risks before, during, and after disasters, including giving them access to life saving services. By definition, people with chronic diseases have ongoing medical needs that can easily be disrupted in a disaster situation. While further evidence is required in this area, a recent systematic review (Ochi et al. 2014) revealed that a considerable number of patients lose their medication during evacuation, many lose essential medical aids such as insulin pens, and many do not even have a record of their prescriptions with them when evacuated. Understanding the impact of medication loss may lead to raising awareness and better preparation among patients and health care professionals. Those with chronic diseases could have worse outcomes and many risk dying when their medication is not available. More research is needed on the impact of disasters on people with chronic care needs, including those with physical or mental disabilities, although mental health is receiving growing attention as a key element of recovery. For the public health community, how to share the learning from the recent systematic review to inform evidence-based policies is of concern.

\subsection{Mental Health Impacts Following Disasters}

The need to enhance recovery schemes by including the provision of psychosocial support and mental health services is also part of the current draft of the post-2015 agreement. Rapid and extensive changes occur in people's lives and the worlds in which they live when they are exposed to extreme events and disasters. These can cause great stress to people, families, and communities because of their inherent effects, such as causing short-term fear of death and other mental health disorders (Williams and Drury 2011). People's abilities to rebuild, recover, and adapt following a disaster are determined by their physical, psychological, and social characteristics, as well as the characteristics of, and support they receive from, their families and the communities in which they live (Ochi et al. 2014). Primary stressors inherent in many disasters can include injuries sustained or watching someone die. The literature recognizes the distress that primary stressors cause and their association with mental disorders. Secondary stressors such as lack of financial assistance, the grueling process of submitting an insurance claim, parents' worries about their children, and continued lack of infrastructure can manifest their effects shortly after a disaster and persist for extended periods of time. The roles of secondary stressors in affecting people's longer-term mental health should not be overlooked (Williams and Drury 2011).

The UK Department of Health in England (DH) (UK Department of Health 2009), the North Atlantic Treaty Organization (NATO), and the Euro-Atlantic Partnership Council (EAPC) (NATO and EAPC 2009) clearly differentiate between distress and mental disorders following a disaster. The threshold between what might be considered a common or anticipated response of distress, and what is indicative of a person developing a mental disorder, are difficult to define and the pathways are complex. Further research is needed to enhance our knowledge and to improve outcomes.

\section{Opportunities for Public Health as Part of the Post- 2015 Framework for Disaster Risk Reduction}

The three UN landmark agreements of the Post-2015 Framework for Disaster Risk Reduction, the Sustainable Development Goals, and the climate change agreements of the Conference of Parties to the UNFCCC all include public health as a theme running through the global negotiations.

Health professionals could be more actively engaged in these international processes to ensure that health issues are addressed as clearly as possible. They can do this by supporting greater consideration of health outcomes and articulating the links with socioeconomic determinants; highlighting the scientific evidence and available data on the impact of disasters on health outcomes; and helping to understand and develop the role of the health sector and strengthening the planning processes, for example by participating in an international partnership to mobilize science for action on DRR and resilience building (Murray 2014).

The relevance of science and the effective use of scientific evidence are fundamental to improving management and supporting decision-making aimed at disaster risk reduction and is very much part of the opportunities for public health. A call for stronger scientific underpinning of actions towards disaster risk reduction and resilience building has been articulated by many member states and stakeholders in numerous consultations. An enhanced contribution of science and technology in the implementation of the Post-2015 Framework for Disaster Risk Reduction could focus on the following four main functions:

(1) Assessment of current state of data availability and scientific knowledge on disaster risks and resilience (what is known, what is not known, what are the uncertainties, and so on).

(2) Synthesis of scientific, including public health, evidence in a timely, accessible, and tailor-made manner. 
(3) Scientific and public health advice to decision-makers through close collaboration and dialogue to identify needs from policy and decision-makers at national and local levels, and review policy options based on scientific evidence.

(4) Monitoring and review, ensuring that scientific data and information can support and be used in data collection and monitoring progress towards disaster risk reduction and resilience building.

In addition, two cross-cutting capabilities would need to be strengthened to ensure an effective science-policy interface:

- Communication and engagement of policy-makers and stakeholders in science, technology, and public health to ensure needs are identified and met, and conversely, a stronger involvement of scientists in policy processes to provide scientific evidence and advice.

- Capacity development to ensure that all countries can have access and use effectively scientific and public health information.

Acknowledgments We acknowledge the help and support of the Third World Conference on Disaster Risk Reduction's Major Group on Science and Technology, organized by the International Council of Science and its many partners, and its voluntary commitment for the conference.

Open Access This article is distributed under the terms of the Creative Commons Attribution License which permits any use, distribution, and reproduction in any medium, provided the original author(s) and the source are credited.

\section{References}

Basher, R. 2013. Science and technology and disaster risk reduction: A review of application and coordination needs. Geneva: UNISDR. http://www.preventionweb.net/posthfa/documents/Scie nce-and-Technology-for-Disaster-Risk-Reduction.pdf. Accessed 24 Jan 2015.

Bayntun, C.A. 2012. Health system approach to all-hazards disaster management: A systematic review. PLOS Currents Disasters. doi:10.1371/50081cad5861d.

Bayntun, C., G. Rockenschaub, and V. Murray. 2012. Developing a health system approach to disaster management: A qualitative analysis of the core literature to complement the WHO toolkit for assessing health-system capacity for crisis management. PLOS Currents Disasters. doi:10.1371/5028b6037259a.

CDC (Centers for Disease Control and Prevention). 2011. Ten great public health achievements worldwide, 2001-2010. Morbidity and Mortality Weekly. 60: 814-818. http://www.cdc.gov/mmwr/ preview/mmwrhtml/mm6024a4.htm. Accessed 23 Jan 2015.

De Groeve, T., K. Poljansek, and L. Vernaccini. 2013. Recording disaster losses: Recommendations for a European approach. Publications office of the European Union, scientific and technical research reports EUR 26111. doi:10.2788/98653. http:// publications.jrc.ec.europa.eu/repository/handle/111111111/29296. Accessed 24 Jan 2015.
Drury, J., S. Reicher, H. Carter, C. Cocking, R. Amlôt, G.J. Rubin, R. and Williams. 2014. Recognising and understanding collective resilience in crowds of survivors, London, UK. UNISDR Scientific and Technical Advisory Group Case Studies. http:// www.preventionweb.net/files/workspace/7935_collectiveresilien ceincrowdsofsurvi.pdf. Accessed 24 Jan 2015.

European Commission. 2014a. Communication from the Commission to the European Parliament, the Council, the European Economic and Social Committee and the Committee of the Regions. The post 2015 hyogo framework for action: Managing risks to achieve resilience. COM (2014) 216 final. 8.4.2014. http://ec. europa.eu/echo/files/news/post_hyogo_managing_risks_en.pdf. Accessed 24 Jan 2015.

European Commission. 2014b. Commission staff working document. Overview of natural and man-made disaster risks in the EU. Accompanying the document communication from the Commission to the European Parliament, the Council, the European Economic and Social Committee and the Committee of the Regions. The post 2015 hyogo framework for action: Managing risks to achieve resilience. COM (2014) 216 final. 8.4.2014. SWD(2014) 134 final. http://www.sos112.si/slo/tdocs/eu_risks_ overview.pdf. Accessed 24 Jan 2015.

Evidence Aid. 2014. Providing resources for decision-makers before, during and after disasters and other humanitarian emergencies. Who we are. http://www.evidenceaid.org/who-we-are/. Accessed 24 Jan 2015.

Global Earthquake Model. 2014. What we do. http://www.globalqua kemodel.org/what/. Accessed 24 Jan 2015.

Global Facility for Disaster Reduction and Recovery. 2014. Who we are. https://www.gfdrr.org/. Accessed 24 Jan 2015.

Greenhalgh, T. 2014. Evidence based medicine: A movement in crisis? BMJ 2014(348): g3725.

IPCC (Intergovernmental Panel on Climate Change). 2012. Managing the risks of extreme events and disasters to advance climate change adaptation. A special report of Working Groups I and II of the Intergovernmental Panel on Climate Change, ed. C. B. Field, V. Barros, T. F. Stocker, D. Qin, D. J. Dokken, K. L. Ebi, M. D. Mastrandrea, K. J. Mach, G.-K. Plattner, S. K. Allen, M. Tignor and P. M. Midgley. Cambridge: Cambridge University Press. http://www.ipcc-wg2.gov/SREX/. Accessed 24 Jan 2015.

Klinger, C., O. Landeg, and V. Murray. 2014. Power outages, extreme events and health: A systematic review of the literature from 2011-2012. PLOS Currents Disasters. doi:10.1371/currents.dis. 04eb1dc5e73dd1377e05a10e9edde673.

Murray, V. 2014. Disaster risk reduction, health, and the post-2015 United Nations landmark agreements. Disaster Medicine and Public Health Preparedness 8(4): 283-287.

NATO (North Atlantic Treaty Organization) and EAPC (EuroAtlantic Partnership Council). 2009. Psychosocial care for people affected by disasters and major incidents: A model for designing, delivering and managing psychosocial services for people involved in major incidents, conflict, disasters and terrorism. Brussels: NATO.

NICE (The National Institute for Health and Care Excellence). 2014. About. http://www.nice.org.uk/about. Accessed 24 Jan 2015.

Nour, N.N. 2011. Maternal health considerations during disaster relief. Reviews in Obstetrics and Gynecology 4(1): 22-27.

Ochi, S., S. Hodgson, O. Landeg, L. Mayner, and V. Murray. 2014. Disaster-driven evacuation and medication loss: A systematic literature review. PLOS Currents Disasters. doi:10.1371/cur rents.dis.fa417630b566a0c7dfdbf945910edd96.

PreventionWeb. 2014. PreventionWeb. Serving the information needs of the disaster risk reduction community. http://www.prevention web.net/english/. Accessed 24 Jan 2015.

Southgate, R.J., C. Roth, J. Schneider, P. Shi, T. Onishi, D. Wenger, W. Amman, L. Ogallo, et al. 2013. Using science for disaster 
risk reduction. Report of the UNISDR Scientific and Technical Advisory Committee. UNISDR. http://www.preventionweb.net/ go/scitech. Accessed 24 Jan 2015.

The Cochrane Collaboration. 2014. About us. http://www.cochrane. org/about-us. Accessed 24 Jan 2015.

UK Department of Health. 2007. Health building note 00-07: Resilience planning for the healthcare estate. Leeds.

UK Department of Health. 2009. NHS emergency planning guidance: Planning for the psychosocial and mental health care of people affected by major incidents and disasters: Interim national strategic guidance. London: Department of Health.

UK Government Cabinet Office. 2013. National risk register of civil emergencies 2013 edition. https://www.gov.uk/government/ uploads/system/uploads/attachment_data/file/211867/NationalRi skRegister2013_amended.pdf. Accessed 22 Jan 2015.

UN (United Nations). 2013. United Nations general assembly 68th session. Resolution adopted by the General Assembly on 20 December 2013; International Strategy for Disaster Reduction. A/RES/68/211. http://www.unisdr.org/files/resolutions/ARES6 8211E.pdf. Accessed 24 Jan 2015.

UN (United Nations). 2014a. United Nations sustainable development knowledge platform. Outcome document-Open working group on sustainable development goals. 21 July 2014. http://sust ainabledevelopment.un.org/content/documents/4518SDGs_FINAL_ Proposal\%20of\%20OWG_19\%20July\%20at\%201320hrs.pdf. Accessed 23 Jan 2015.

UN (United Nations). 2014b. United Nations General Assembly third United Nations World conference on disaster risk reduction. Outcome of fifth Africa regional platform for disaster risk reduction, 13-16 May 2014, Abuja, Nigeria. A/CONF.224/PC(I)/ 7. http://wcdrr.org/documents/wcdrr/prepcom1/outcomes/Outcome\% 20of\%20Fifth\%20Africa\%20Regional\%20Platform\%20for\%20Dis aster\%20Risk_EN.pdf. Accessed 21 Jan 2015.

UN (United Nations). 2014c. United Nations General Assembly third United Nations World conference on disaster risk reduction. Outcome of fourth session of the regional platform for disaster risk reduction in the Americas, 27-29 May 2014, Guayaquil, Ecuador. A/CONF.224/PC(I)/8. http://wcdrr.org/documents/wc drr/prepcom1/outcomes/OUTCOME\%20OF\%20FOURTH\%20 SESSION\%20OF\%20THE\%20REGIONAL\%20PLATFORM\% 20FOR\%20DISASTER\%20RISK\%20REDUCTION\%20IN\% 20THE\%20AMERICAS_EN.pdf. Accessed 24 Jan 2015.

UN (United Nations). 2014d. United Nations General Assembly third United Nations World conference on disaster risk reduction. Sixth session of the pacific platform for disaster risk management. The way forward: Climate and disaster resilient development in the Pacific, 2-4 June 2014, Suva, Fiji. Meeting statement. A/CONF. 224/PC(I)/9. http://wcdrr.org/documents/wcdrr/prepcom1/out comes/Outcome $\% 20$ of $\% 20$ Sixth $\% 20$ Session $\% 20$ of $\% 20$ the $\% 20$ Pacific\%20Platform\%20for\%20Disaster_EN.pdf. Accessed 24 Jan 2015.

UN (United Nations). 2014e. United Nations General Assembly third United Nations World conference on disaster risk reduction. Outcome of sixth Asian ministerial conference on disaster risk reduction, 22-26 June 2014, Bangkok, Thailand. A/CONF.224/ PC(I)/11. http://6thamcdrr-thailand.net/6thamcdrr/Portals/0/Final\%20 Bangkok\%20Declaration\%20-6\%20AMCDRR\%20-final\%2026\% 20June-0800\%20hours.pdf. Accessed 24 Jan 2015.

UN (United Nations). 2014f. United Nations General Assembly third United Nations World conference on disaster risk reduction. Outcome of the European ministerial meeting on disaster risk reduction. A/CONF.224/PC(I)/12. http://wcdrr.org/documents/ wcdrr/prepcom $1 /$ outcomes/outcome $\% 20$ of $\% 20$ european $\% 20 \mathrm{~min}$ isterial\%20meeting_en.pdf. Accessed 24 Jan 2015.

UN (United Nations). 2014g. UN sectoral brief -Health and disaster risk. A contribution by the United Nations to the consultation leading to the third World Conference on disaster risk reduction (WCDRR). http://www.wcdrr.org/documents/wcdrr/prepcom1/ UN/ATTR8FWA.pdf. Accessed 24 Jan 2015.

UN (United Nations). 2014h. Third UN World conference On disaster risk reduction 14-18 March 2015-Sendai, Japan Major Groups Organizing Partners. http://www.wcdrr.org/majorgroups/organi zingpartners. Accessed 21 Jan 2015.

UNISDR (United Nations International Strategy for Disaster Reduction). 2007. Hyogo framework for action 2005-2015: Building the resilience of nations and communities to disasters. Extract from the final report of the World conference on disaster reduction (A/CONF.206/6). http://www.unisdr.org/files/1037_ hyogoframeworkforactionenglish.pdf. Accessed 24 Jan 2015.

UNISDR (United Nations International Strategy for Disaster Reduction). 2013. Disaster impacts/2000-2012. http://www.prevention web.net/files/31737_20130312disaster20002012copy.pdf. Accessed 24 Jan 2015.

UNISDR (United Nations International Strategy for Disaster Reduction). 2014a. Africa regional platform plenary: Stakeholder consultation reports statement from the Scientific, Technical and Academic Communities in disaster risk reduction (5th African Regional Platform, Abuja, Nigeria). 2014. http://www.unisdr. org/files/37777_11.sciencetechnologyacademicgroup.pdf. Accessed 24 Jan 2015.

UNISDR (United Nations International Strategy for Disaster Reduction). 2014b. UNISDR Regional Office for the Americas (UNISDR-Americas) and the Republic of Ecuador, through the Secretariat of risk management and the Ministry of foreign affairs reflections of the representatives of the scientific, technical and academic sector who participated in the fourth session of the regional platform for disaster risk reduction in the Americas, Guayaquil, Ecuador, 27-29 May 2014. http://www. eird.org/pr14-eng/docs/science-statement-V3-English.pdf. Accessed 24 Jan 2015.

UNISDR (United Nations International Strategy for Disaster Reduction). 2014c. Outcome documents statement of voluntary commitments of Asia science, technology and academia stakeholder group for the 6th Asian ministerial conference for disaster risk reduction, 22-26 June 2014, Bangkok, Thailand. http:// 6thamcdrr-thailand.net/6thamcdrr/Portals/0/Annex\%2010\%20$\% 20$ Science $\% 20$ Tech $\% 20$ and $\% 20$ Academia $\% 20$ Final $\% 2026 \%$ 20June\%202014.pdf. Accessed 24 Jan 2015.

UNISDR (United Nations International Strategy for Disaster Reduction). 2014d. Coherence and mutual reinforcement between a post-2015 framework for disaster risk reduction, Sustainable Development Goals and the Conference of Parties to the UNFCCC. http://www.preventionweb.net/documents/posthfa/ Mutual_reinforcement_of_2015_Agendas_UNISDR.pdf. Accessed 24 Jan 2015.

World Health Assembly. 2011. 64th World Health Assembly agenda item 13.4 - Strengthening national health emergency and disaster management capacities and resilience of health systems. http:// apps.who.int/gb/ebwha/pdf_files/WHA64/A64_R10-en.pdf. Accessed 24 Jan 2015.

WHO (World Health Organization). n.d. Public health. http://www. who.int/trade/glossary/story076/en/. Accessed 24 Jan 2015.

WHO (World Health Organization). 2002. Gender and health in disasters 2002. http://www.who.int/gender/other_health/en/gen derdisasters.pdf. Accessed 24 Jan 2015.

WHO (World Health Organization). 2005a. Gender and health in disasters. http://www.who.int/gender/other_health/disasters/en/. Accessed 24 Jan 2015.

WHO (World Health Organization). 2005b. International health regulations. Alert, response, and capacity building under the international health regulations (IHR), 2nd edn. http://www.who. int/ihr/publications/9789241596664/en/. Accessed 24 Jan 2015. 
WHO (World Health Organization). 2005c. Gender considerations in disaster assessment. http://www.who.int/gender/gwhdisasteras sessment2.pdf?ua=1. Accessed 24 Jan 2015.

WHO (World Health Organization). 2007. Everybody's business. Strengthening health systems to improve health outcomes: WHO's framework for action. http://www.who.int/healthsys tems/strategy/everybodys_business.pdf. Accessed 24 Jan 2015.

WHO (World Health Organization). 2008. Report of the WHO commission on the social determinants of health-final report. http://www.who.int/social_determinants/thecommission/finalre port/en/. Accessed 24 Jan 2015.

WHO (World Health Organization) Europe. 2011. Assessment of health-system crisis preparedness: England. http://www.euro. who.int/_data/assets/pdf_file/0008/167822/England_report. pdf?ua=1. Accessed 24 Jan 2015.

WHO (World Health Organization) Europe. 2012a. Strengthening health-system emergency preparedness. Toolkit for assessing health-system capacity for crisis management. Part 1. User manual 2012 ISBN 978928900261 5. http://www.euro.who. int/_data/assets/pdf_file/0008/157886/e96187.pdf. Accessed 24 Jan 2015.
WHO (World Health Organization) Europe. 2012b. Strengthening health-system emergency preparedness. Toolkit for assessing health-system capacity for crisis management. Part 2. Assessment form 2012 ISBN 978928900262 2. http://www.euro.who. int/_data/assets/pdf_file/0010/157888/e96188.pdf?ua=1. Accessed 24 Jan 2015.

WHO (World Health Organization), PHE (Public Health England), UNISDR (United Nations International Strategy for Disaster Reduction). 2012. Humanitarian action. Disaster risk management for health fact sheets. http://www.who.int/hac/techgui dance/preparedness/factsheets/en/. Accessed 24 Jan 2015.

Williams, R., and J. Drury. 2011. Personal and collective psychosocial resilience: Implications for children, young people and their families involved in war and disasters. In Children, and armed conflict, ed. D. Cook, J. Wall, and P. Cox. Basingstoke and New York: Palgrave McMillan.

Young, K., D. Ashby, A. Boaz, and L. Grayson. 2002. Social science and the evidence-based policy movement. Social Policy and Society 1(3): 215-224. 